\title{
„MIEJSCE CIENIEM KRYTE” W DOMU NR 4 Z KOŚCIELISK, POW. OLESNO, WOJ. OPOLSKIE (PRÓBA REKONSTRUKCJI) - PROBLEM BUDOWNICTWA PODCIENIOWEGO W KULTURZE PRZEWORSKIEJ
}

\author{
'A SHADOW-COVERED PLACE' IN THE HOUSE NO. 4 \\ FROM KOŚCIELISKA, OLESNO DISTRICT, OPOLE VOIVODESHIP \\ (RECONSTRUCTION ATTEMPT) - A PROBLEM OF THE ARCADED \\ ARCHITECTURE OF THE PRZEWORSK CULTURE
}

\author{
Andrzej Michatowski \\ Instytut Prahistorii, Uniwersytet im. Adama Mickiewicza \\ Św. Marcin 78, 61-809 Poznań, Poland
}

\begin{abstract}
The article brings about another attempt to reconstruct the shape of house No. 4 from Kościeliska, Olesno district (Hedwigstein, Kr. Rosenberg) within the context of arcaded houses noticed at the Przeworsk culture settlements.

The undertaken analysis makes possible a reinterpretation of the already published materials and proposes a new research strategy that addresses this issue more efficiently. This makes it possible to prove the existence of corner arcades in the architecture of the Przeworsk culture.
\end{abstract}

„Miejsce cieniem kryte” - tak twórca Stownika języka polskiego M.S.B. Linde w roku 1858 określił podcienie ${ }^{1}$ - architektoniczny szczegół domostwa, jeszcze do niedawna tak popularny w krajobrazie wiejskiej zabudowy drewnianej. Idea podcieni nie jest wszakże pomysłem ostatnich kilkuset lat nowożytności. To rozwiązanie konstrukcyjne, mające niewątpliwie ogromne walory estetyczne, posiadało przecież w zasadzie przede wszystkim swoje znaczenie czysto funkcjonalne i praktyczne. Jego „prahistoria” zapisana jest setkami dołków posłupowych, rozsianych na licznych osadach pradziejowych.

Niniejszy artykuł ma na celu zwrócenie uwagi na jakże często występujące, a traktowane marginalnie przez badaczy, funkcjonowanie podcieni w budownictwie kultury przeworskiej. Jest on zarazem próbą reinterpretacji, nowego spojrzenia oraz

\footnotetext{
${ }^{1}$ Linde 1858.
} 
rekonstrukcji jednego $\mathrm{z}$ takich budynków podcieniowych, opartą na opublikowanym i od dawna funkcjonującym w literaturze archeologicznej domostwie $\mathrm{nr} 4 \mathrm{z}$ osady kultury przeworskiej w Kościeliskach, pow. Olesno, woj. opolskie ${ }^{2}$.

\section{POLOŻENIE STANOWISKA I HISTORIA BADAŃ}

Stanowisko $1 \mathrm{w}$ Kościeliskach położone było na łagodnym, lewym skłonie doliny Prosny. Osada ograniczona była od północy i północnego wschodu pasmem podmokłych łąk terasy zalewowej Prosny, od południa zaś łączącym się prostopadle $\mathrm{z}$ jej doliną obniżeniem ${ }^{3}$. Stanowisko w Kościeliskach (przed wojną Hedwigstein, Kr. Rosenberg) pierwszy raz badane było od 26 sierpnia do 2 października 1937 roku przez preparatora T. Kubiczka ze Schlesischen Grenzlandsmuseum w Bytomiu. Opiekę naukową nad badaniami sprawował dyrektor tegoż muzeum, dr F. Pfützenreiter. Badania zaowocowały odkryciem, jak wówczas to określono, „osady kultury dobrodzieńskiej (Guttentager Kultur)", na której zarejestrowano 9 ,jam wczesnodziejowych" oraz 4 ,domy germańskie”, Wyniki tych badań zostały opracowane przez F. Hufnagla i opublikowane w „Altschlesien” w roku $1940^{5}$. Po wojennych zmianach granic i wejściu tych terenów Śląska w skład państwa polskiego, badania na stanowisku w Kościeliskach kontynuował Z. Trudzik ${ }^{6}$, który w trzech kampaniach terenowych w latach 1957, 1959 i 1960 odsłonił większą część osady (114 arów), odkrywając nań dalsze obiekty (łącznie 111). Spośród tych obiektów 48 zinterpretowanych zostało jako pozostałości budynków mieszkalnych: 6 o konstrukcji słupowej i zrębowej, 1 lub 2 (?) jako półziemianki, 2 jako ziemianki, 3 jako obiekty specjalne o niewiadomej funkcji (określone jako resztki budynków) oraz ,jamy nie do zakwalifikowania"7. Na podstawie odkrytych materiałów (głównie ceramiki) osada datowana jest na V w. n.e. ${ }^{8}$

\section{DOM 4}

Chata 4 odkryta została w roku 1937. Położona była w północnej partii stanowiska (ryc. 1) pomiędzy jamą 7 a jamą 8, przylegającymi i częściowo przecinającymi chatę od południowego wschodu (jama 7) i południowego zachodu (jama 8). Zarys budynku ukazał się na głębokości $30 \mathrm{~cm}$ od poziomu humusu, w postaci przebarwie-

\footnotetext{
${ }^{2}$ Hufnagel 1940; Trudzik 1959a; Godłowski 1969; Jadczykowa 1981.

${ }^{3}$ Hufnagel 1940, s. 84; Trudzik 1959a, s. 65.

${ }^{4}$ Hufnagel 1940.

${ }^{5}$ Hufnagel 1940.

${ }^{6}$ Trudzik 1959a; $1959 \mathrm{~b} ; 1960$.

${ }^{7}$ Trudzik 1960, s. 27.

${ }^{8}$ Trudzik 1959a, s. 103; 1960, s. 29.
} 


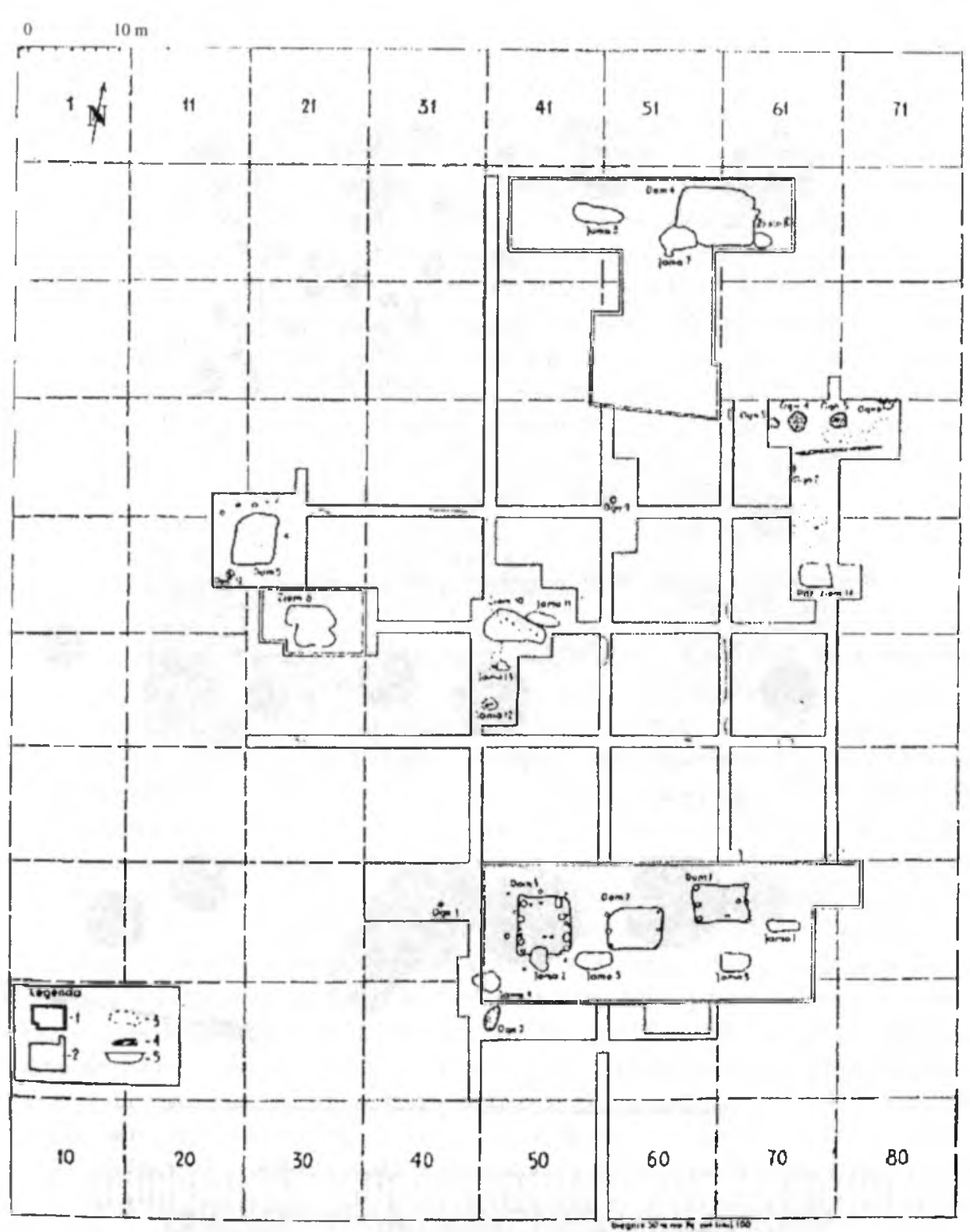

Ryc. 1. Kościeliska, pow. Olesno, woj. opolskie. Plan zbiorczy osady (wg Trudzik 1959a) Abb. 1. Kościeliska, Kr. Olesno, Woi. Opole. Übersichtsplan der Siedlung (nach Trudzik 1959a)

nia kształtu prostokątnego, o długości $6 \mathrm{~m}$ (W-E) i szerokości 4,7 m (N-S). Północno-wschodni narożnik chaty był półkoliście ścięty. Na tymże poziomie, we wnętrzu wypełniska, koło północno-zachodniego narożnika odsłonięto palenisko. Jego ślady 

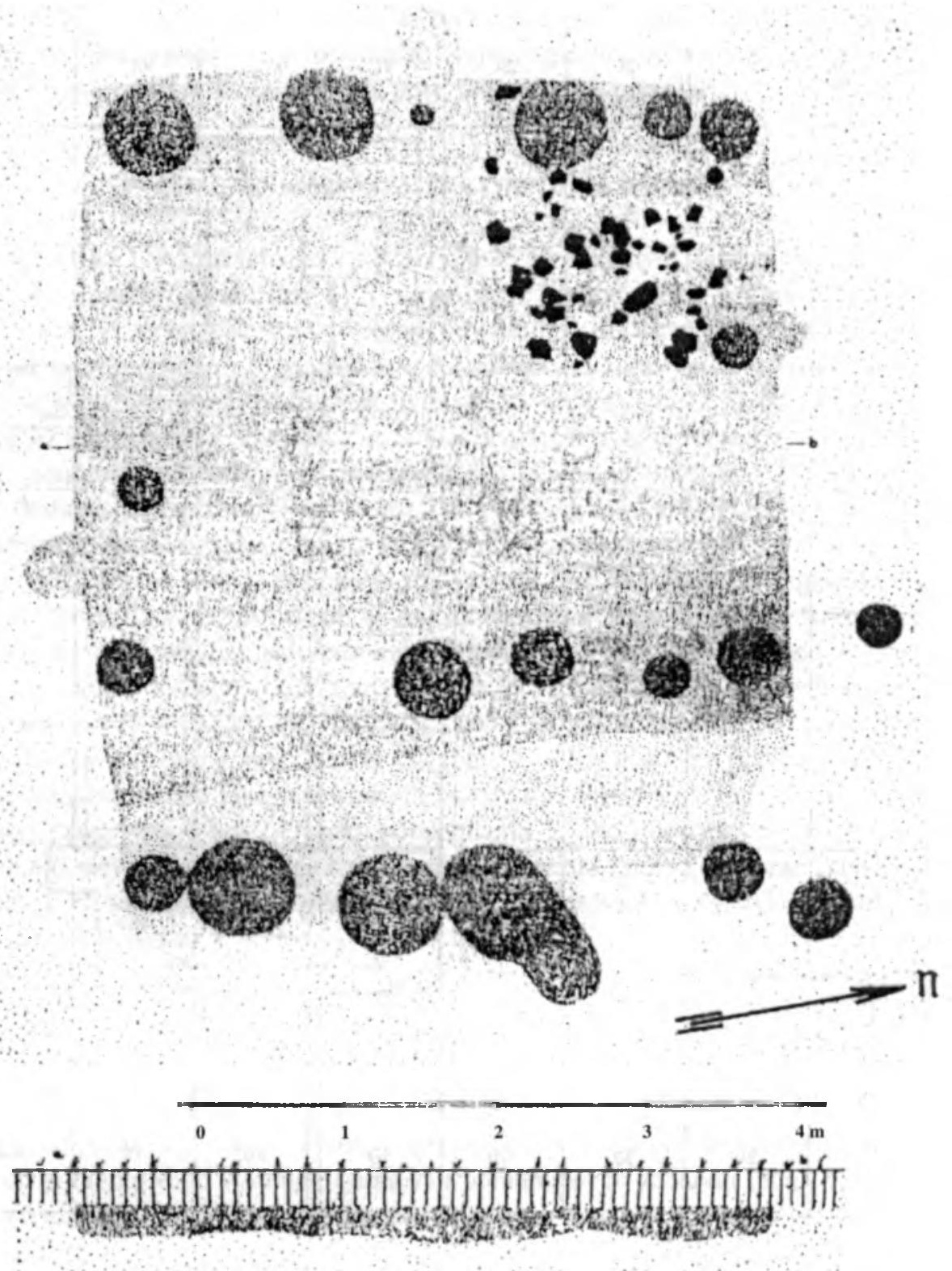

Ryc. 2. Kościeliska, pow. Olesno, woj. opolskie. Plan domu nr 4 (wg Hufnagel 1940) Abb. 2. Kościeliska, Kr. Olesno, Woi. Opole. Plan des Hauses Nr. 4 (nach Hufnagel 1940) 
tworzyły przepalone polne kamienie, luźno ułożone, pomiędzy którymi odkryto liczną ceramikę, żelazny nóż oraz przęślik. Na głębokości $40 \mathrm{~cm}$ od poziomu humusu zarys jamy zmniejszył się w części wschodniej o około $1,1 \mathrm{~m}$ - do $4,9 \mathrm{~m}$ długości. Zmniejszeniu uległa również szerokość wypełniska - o około $10 \mathrm{~cm} \mathrm{z} \mathrm{obu} \mathrm{stron.}$ $\mathrm{Na}$ głębokości $50 \mathrm{~cm}$ od poziomu humusu wypełnisko jamy chaty zanikło całkowicie. Ukazało się natomiast 20 doskonale czytelnych w calcu dołków posłupowych'. Łączna liczba słupów związanych $\mathrm{z}$ chatą wynosiła jednakże moim zdaniem 21 . Największy dołek posłupowy ze ściany wschodniej jest bez wątpienia efektem procesów podepozycyjnych, które spowodowały „zlanie się” dwu zlokalizowanych koło siebie jam posłupowych $w$ jedną dużą. $Z$ tych 21 słupów po 6 wystapiło wzdłuż ścian krótszych (wschodniej i zachodniej). Na ścianach dłuższych pomiędzy słupami narożnikowymi wystapiły po 2 słupy; 3 słupy zarejestrowano we wnętrzu chaty w jej wschodniej partii, w przybliżeniu w miejscu, gdzie nastapił szybszy zanik wypełniska jamy. Trzy słupy znajdowały się na zewnątrz chaty (ryc. 2).

\section{DOTYCHCZASOWE INTERPRETACJE KONSTRUKCJI DOMU 4}

W dotychczasowych opracowaniach budowla $4 \mathrm{z}$ Kościelisk interpretowana była najczęściej jako chata słupowa, dwuczęściowa. F. Hufnagel sugerował dwupodział chaty na izbę główną i przedsionek, związany m.in. z obniżeniem poziomu jamy oraz z wystapieniem ,ścianki działowej”. Jego zdaniem słup na wysokości wewnętrznego przepierzenia byłby po prostu jego przedłużeniem i spełniałby zadanie wiatrochronu ${ }^{10}$. K. Godłowski w monograficznym opracowaniu budownictwa i rozplanowania osad kultury przeworskiej na Śląsku widzi w domu 4 z Kościelisk „dwuczęściową półziemiankę z silnie wgłębioną częścią wewnętrzną" ", sugerując możliwość funkcjonowania w niej zarówno otwartego podcienia, jak i zamkniętego przedsionka, oddzielonego przepierzeniem od właściwego domu. Jednak w swych dalszych rozważaniach skłania się bardziej ku tej drugiej możliwości, nie wykluczając jednak funkcjonowania jakiegoś „,rodzaju ganku” przy wejściu, ewentualnie dwu wejściach ${ }^{12}$. Wreszcie I. Jadczykowa w swoim zbiorczym opracowaniu budownictwa ludności kultury przeworskiej z obszaru Polski określa budynek w Kościeliskach jako „dom dwuczęściowy z silnie zagłębioną częścią wewnętrzna" "13. Uważa ona, iż dom ten zbudowany był w konstrukcji sumikowo-łątkowej, lecz sugeruje również zastosowanie - głównie we wschodniej partii domu, ścian o konstrukcji plecionkowej, zwłaszcza tam, gdzie jest gęste rozstawienie słupów ${ }^{14}$.

\footnotetext{
${ }^{9}$ Hufnagel 1940 , s. $97-99$.

${ }^{10}$ Hufnagel 1940, s. 98.

"I Godłowski 1969, s. 312.

${ }^{12}$ Godlowski 1969, s. 320, 321.

13 Jadczykowa 1981, s. 135.

${ }^{14}$ Jadczykowa 1981, s. 199, 200.
} 


\section{PRÓBA REINTERPRETACJI I REKONSTRUKCJI DOMU 4}

Przystępując do rekonstrukcji chaty 4 z Kościelisk staję, niestety, wobec trudności wynikających $\mathrm{z}$ nieścisłości i dwuznaczności terminologii dotyczącej form budynków, jaka panuje w literaturze archeologicznej. Brak bowiem ogólnie przyjętych kryteriów odróżniania budynków naziemnych od zagłębionych, tych zaś od pólziemianek, które często są łączone $w$ jedną grupę z ziemiankami. Wprowadzane przez różnych badaczy kryteria głębokościowe wobec ich subiektywności są mało przydatne. Przykładowo: jako pólziemianki J. Kaźmierczyk określa budynki zagłębione na $0,45-0,6 \mathrm{~m}^{15}$, gdy I. Jadczykowa uznaje zań już obiekty wkopane na $0,2 \mathrm{~m}^{16}$, co przy głębokości $0,4 \mathrm{~m}$ wypełniska ,rezerwowanej” dla budynków naziemnych u K. Dąbrowskiego ${ }^{17}$ najlepiej chyba oddaje ten problem.

Do jakiego typu budownictwa należałoby zatem zaliczyć omawiany tu obiekt? $\mathrm{Na}$ pewno nie jest to silnie zagłębiona półziemianka, jak sugerował K. Godłowski ${ }^{18}$. Za nim prawdopodobnie owe „silne zagłębienie" postulowała I. Jadczykowa ${ }^{19}$. Podana przez K. Godłowskiego w jego zestawieniu budynków z osad śląskich wartość $50 \mathrm{~cm}$ dla głębokości jamy domostwa ${ }^{20}$ jest wartością podaną od poziomu humusu! A jak wynika z opracowania F. Hufnagla, zarys jamy pojawił się $30 \mathrm{~cm}$ pod jego poziomem ${ }^{21}$ ! Zatem miąższość wypełniska w głównej partii chaty wynosiła nie 50 , lecz $20 \mathrm{~cm}$, a w jej wschodniej części $10 \mathrm{~cm}$. Pomijając kryteria głębokościowe jako mało przydatne, co starałem się wyżej wykazać, uważam, iż dom 4 z Kościelisk można $\mathrm{z}$ dużym prawdopodobieństwem zaliczyć do budynków naziemnych. Jak się zatem ma takie określenie typu domostwa do owych $20-10 \mathrm{~cm}$ miąższości wypełniska chaty? Można je uzasadnić następująco. Jeżeli potraktujemy budynek nie w kategorii „martwego" źródła archeologicznego, ale imaginacyjnie ożywimy go na chwilę i zaludnimy, zobaczymy w nim jego mieszkańców - tu śpiących, pracujących, przygotowujących sobie pożywienie, przesiadujacych w nim podczas deszczu, zimy, a więc poruszających (!) się w jego obrębie przez 365 dni w roku, to siłą rzeczy zauważymy, iż piaszczysta podłoga budynku powoli zacznie przekształcać się w warstwę użytkowa, poprzez zwykłe jej zadeptanie! Gdy przemnożymy to przez okres użytkowania budynku, trwający kilka, kilkanaście czy kilkadziesiąt lat, to siłą rzeczy ilość „wdeptanych” w podłoże pozostałości codziennego użytkowania wytworzy ową warstwę wypełniskową a jednocześnie rzeczywiście może o kilka centymetrów obniżyć poziom „podłogi” w stosunku do otoczenia. Za moją koncepcją niezamierzonego „zagłębienia” wnętrza domu 4 przemawia jeszcze jeden istotny

\footnotetext{
${ }^{15}$ Kaźmierczyk 1970, s. 32.

16 Jadczykowa 1975, s. 135.

${ }^{17}$ Dąbrowski - patrz bibliografia na końcu artykułu.

${ }^{18}$ Godłowski 1969, s. 312.

${ }^{19}$ Jadczykowa 1981, s. 135.

${ }^{20}$ Godlowski 1969, s. 312.

${ }^{21}$ Hufnagel 1940, s. 97.
} 
szczegół, który odnotowali przedwojenni badacze omawianego stanowiska. Otóż palenisko, które znajdowało się w północno-zachodnim narożniku chaty, było odkryte na poziomie stropu (!) wypełniska ${ }^{22}$, co w przypadku intencjonalnego zagłębienia chaty byłoby przecież fizycznie niemożliwe, a ślady paleniska musiałyby wystapić w spagu warstwy lub w stropie calca (gdzie ich nie ma).

Określiwszy typ domostwa należałoby zatem przejść do jego konstrukcji. Bezsporny wydaje się fakt, iż mamy tu do czynienia z budynkiem słupowym, negatywy po słupach są bowiem doskonale czytelne (ryc. 2). Problem pojawia się dopiero przy próbie odtworzenia wyższych partii omawianego budynku. Niestety, nie zachowały się ślady, które pozwoliłyby zrekonstruować sposób budowy ścian (np. polepa konstrukcyjna z odciśniętymi negatywami belek czy plecionki). Uzasadniona wydaje się obserwacja I. Jadczykowej o możliwości wzniesienia ścian w konstrukcji sumikowo-łątkowej oraz - być może tam, gdzie są gęsto rozstawione słupy - w technice ramowej (plecionka) ${ }^{23}$. Podstawą konstrukcji sumikowo-łątkowej są pionowe słupy - łątki, mające na całej swej długości dwa wyżłobienia (pazy), w które wpuszcza się odpowiednio zaciosane końce poziomych okraglaków, czyli sumików. Nie wszystkie łątki budynku musiały być wbite w ziemię, lecz jedynie te, które miały znaczenie dla stabilności budynku. Technika ta miała wiele walorów: niskie wymagania surowcowe (stosowanie belek różnych wymiarów), możliwość wznoszenia budowli o dowolnych rozmiarach i pod dowolnym kątem w rzucie poziomym ${ }^{24}$. Innym rozwiązaniem wartym rozważenia przy takim rozstawieniu słupów jest możliwość (teoretycznie) wzniesienia ścian w jakiejś prostej odmianie konstrukcji ramowej, w której przestrzenie między belkami wypełniano cienkim, pionowymi sztachetkami, oblepianymi surową gliną wymieszaną z sieczką. Technika ta była jeszcze do niedawna bardzo popularna i szeroko rozprzestrzeniona w budownictwie wiejskim ${ }^{25}$ i nie tylko. Zastosowanie takiej techniki wznoszenia ścian przy tak gęstym rozstawie słupów ścian szczytowych wydaje się być logiczniejsze niż łączenie ich za pomocą krótkich $(20-50 \mathrm{~cm})$ sumików. Chyba że niewielkie przerwy pomiędzy poszczególnymi słupami uzupełniano inną techniką być może plecionką, jak sugerowała I. Jadczykowa. Przeplatanie stosowano głównie w ścianach działowych domostw i ścianach zewnętrznych budynków gospodarczych, ale można założyć, iż niektóre budynki mieszkalne również zewnętrzne ściany mogły mieć plecionkowe ${ }^{26}$. Wysokość ścian w domach ludności kultury przeworskiej jest trudna do ustalenia. J. Pyrgała, uwzględniając analogie etnograficzne, określił ich maksymalną wysokość na 2-2,5 $\mathrm{m}^{27}$. Nad ścianami wznosił się dach. Konstrukcja dachów jest dla archeolo-

\footnotetext{
${ }^{22}$ Hufnagel 1940, s. 97.

${ }^{23}$ Jadczykowa 1981, s. 199, 200.

${ }^{24}$ Moszyński 1967.

${ }^{25}$ Wróblewski 1958, s. 131, 132.

${ }^{26}$ Pyrgała 1972a, s. 224.

${ }^{27}$ Pyrgała 1972b, s. 147.
} 
gów jeszcze większą niewiadomą niż wygląd ściany. Jak do tej pory jedynym odkryciem interpretowanym jako zawalony strop jest warstwa I z chaty XII na osadzie kultury przeworskiej z drugiej połowy III - końca IV w. ze stanowiska II w Siemiechowie, gm. Widawa. Wystapiły tam ślady spalonych belek drewnianych, ułożonych równolegle ${ }^{28}$. Poza tym znaleziskiem jedyną podstawą dla odtworzenia sposobu zadaszania budynków pradziejowych są analogie etnograficzne.

Dach w omawianej chacie miał zapewne konstrukcję dwuspadowa, taka bowiem najlepiej sprawdza się w naszym klimacie i taką też potwierdzają wszystkie źródła etnograficzne (por. Moszyński 1967 i inni). W związku z brakiem w planie domu 4 dwóch słupów umieszczonych na osi podłużnej obiektu, które mogłyby stanowić pozostałość sochy, trzeba wykluczyć rozwiązanie konstrukcji dachowej na sochę i ślemię. Ponieważ jednak zachowały się ślady po słupach narożnych oraz dodatkowych na ścianach krótszych, szczytowych, jak i dłuższych, można - jak określił to Z. Kobyliński - „domyślać się" dachu na półsochy lub o konstrukcji ślegowej ${ }^{29}$. Dach ślegowy jednak konstrukcyjnie powiązany jest $\mathrm{z}$ domostwem zrębowym ${ }^{30}$. Pozostaje zatem dach zbudowany na tzw. półsochach. Sądzę, iż właśnie takie rozwiązanie zostało zastosowane w omawianym obiekcie. Konstrukcja dachu na półsochy jest rozwinięciem formy dachu na sochę i ślemię. Sochy to słupy pionowo wbite w ziemię, naturalnie rozwidlone u góry, na których spoczywało ślemię - pozioma belka wsparta $w$ ich rozwidleniach. Do ślemienia, stanowiącego grzbiet dachu, mocowano żerdzie podtrzymujące jego pokrycie. Na skutek skracania soch szczytowych i zastępowania ich stosunkowo krótkimi słupami wspierającymi się na ostatniej belce szczytowych ścian budynku, wykształciła się sugerowana dla domu 4 w Kościeliskach konstrukcja półsochowa ${ }^{31}$. Samo pokrycie dachu mogło być wykonane ze słomy bądź sitowia (trzciny), te sposoby krycia dachów popularne były jeszcze w dwudziestoleciu międzywojennym, a obecnie zaczynają przeżywać renesans na terenach turystycznych, np. w północnej Francji (Normandia) czy północnych Niemiec (Schleswig-Holstein, Vorpommern). Odpowiednia grubość takiego poszycia gwarantuje nieprzemakanie dachu nawet przy silnych opadach deszczu (czy śniegu) i stanowi doskonałą izolację cieplną (autor miał okazję mieszkać przez ponad półtora miesiąca na poddaszu domu krytego słomą w Putgarten na Rugii, tak podczas upałów przekraczających $30^{\circ} \mathrm{C}$, jak i dwóch wczesnojesiennych, bardzo deszczowych i chłodnych tygodni). Poza tym takie poszycie dachowe jest o wiele lżejsze od gontów, co nie jest bez znaczenia przy wymienianych technikach stawiania ścian. Trudności nie nastręczają również zmiany pokrycia dachu czy jego konieczne reperacje.

\footnotetext{
${ }^{28}$ Jażdżewska 1988, s. 123, 124

${ }^{29}$ Kobyliński 1988, s. 31.

${ }^{30}$ Moszyński 1967.

${ }^{31}$ Moszyński 1967.
} 

1
23
$4 \quad 56$

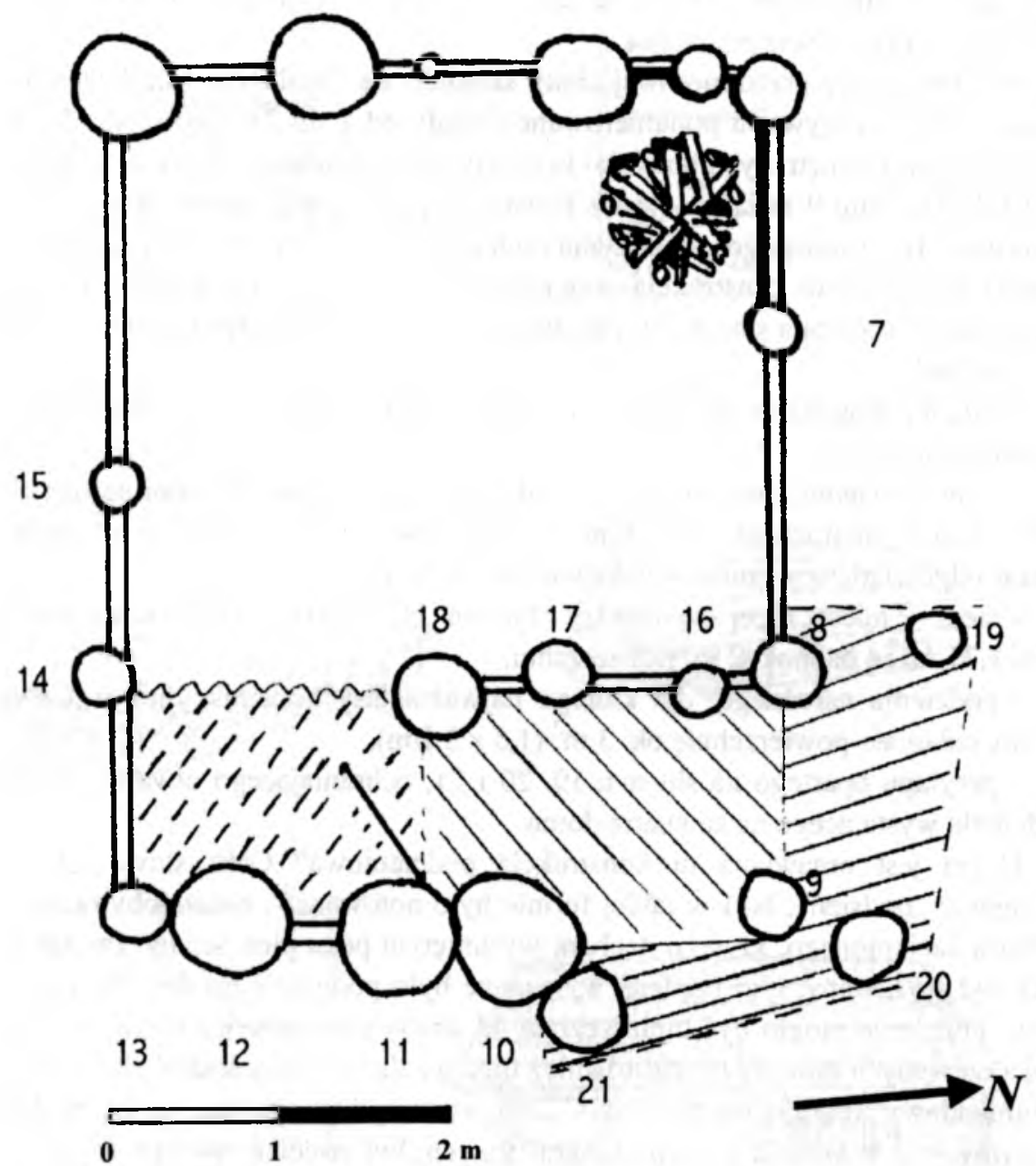

Y 7 sień

dołki posłupowe

$x^{\text {palenisko }}$

МIV podcień

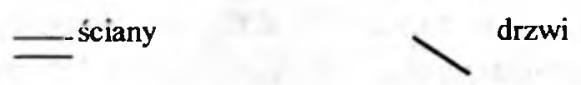

P1 ${ }^{\text {ganek }}$

= $\begin{gathered}\text { ściany wzmacniane } \\ \text { gliną (przy palenisku) }\end{gathered} \sim \begin{aligned} & \text { kotara odgradzająca } \\ & \text { przedsionek od izby }\end{aligned}$

Ryc. 3. Kościeliska, pow. Olesno, woj. opolskie. Rekonstrukcja planu domu nr 4 z przypuszczalnym podziałem wnętrza

Abb. 3. Kościeliska, Kr. Olesno. Woi. Opole. Rekonstruktion des Planes des Hauses Nr. 4 mit vermutlicher Anordnung der Innenräume 
Zamknąwszy dachem przybliżoną bryłę budynku pragnąłbym zająć się teraz tym, co jest tytułowym problemem artykułu, to jest rozplanowaniem domostwa, w tym także obecnością podcienia.

$\mathrm{Na}$ konstrukcję przedmiotowej chaty składało się 21 słupów (dla lepszego zobrazowania toku wywodu ponumerowane zostały od 1 do 21 - zob. ryc. 3). Konstrukcję ścian zewnętrznych budynku tworzyły, moim zdaniem, słupy od 1 do 8 oraz od 10 do 18 . Slup 9 związany jest $z$ konstrukcją podcienia, natomiast słupy 19-21 z konstrukcją wysuniętego „zadaszenia podcienia”, tworzącego rodzaj ganku. Sugerowana przeze mnie konstrukcja podcieniowa mieściła się na wschodniej ścianie szczytowej i wspierała się na jednym słupie. W ten sposób konstruowane są podcienia narożne ${ }^{32}$.

Chata 4 z Kościelisk składałaby się w takim układzie z czterech współgrających ze sobą elementów:

- w przybliżeniu kwadratowej izby głównej ograniczonej słupami narożnymi 1 , $6,8,14$, o wymiarach ok. $4 \times 3,8 \mathrm{~m}$, co daje powierzchnię około $15 \mathrm{~m}^{2}$ (byłby to obszar odpowiadający grubszej warstwie kulturowej),

- sieni - mieszczącej się między słupami 11, 13, 14 i 18, o wymiarach ok. $1,2 \times 1,75 \mathrm{~m}$, co daje ok. $2 \mathrm{~m}^{2}$ powierzchni,

- podcienia narożnego, dla którego najważniejszy konstrukcyjnie jest słup 9 , a które osłaniało powierzchnię ok. $3 \mathrm{~m}^{2}(1,5 \times 2,1 \mathrm{~m})$,

- przyłapu opartego na słupach 19, 20 i 21, ochraniającego otwartą przestrzeń podcienia wystającego na zewnątrz domu.

Czym jest omawiana tu konstrukcja podcieniowa? Otóż słowo „podcień” względnie „podsień”, bo i w takiej formie było notowane ${ }^{33}$, należałoby odnieść do obszaru zacienionego, krytego dachem wysuniętym poza pion ściany. Im dalej taki dach był wysuwany, tym bardziej wymagane było podparcie go dodatkowymi słupami. Podcienie mogło być umieszczone od strony szczytowej, tworząc osłonę dla zlokalizowanych tam drzwi, jak również biec wzdłuż licowej ściany chaty, tworząc

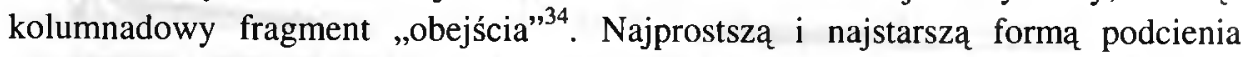
szczytowego, w świetle ustaleń etnograficznych, był podcień otwarty, trójsłupowy. Był on najbardziej rozpowszechniony w budownictwie ludowym obok bezsłupowych podcieni przyzbowych (ryc. 4c). Zredukowaną formą podcienia pełnego jest podcień narożny, opierający się z reguły na jednym, bardzo rzadko na dwu słupach (ryc. 4b, 5). Dążenie do redukcji podcienia mogło być związane $\mathrm{z}$ chęcią wykorzystania krytej przestrzeni na cele gospodarcze lub mieszkalne ${ }^{35}$. Taką właśnie konstrukcję obserwujemy w domu 4 z Kościelisk.

\footnotetext{
${ }^{32}$ Wróblewski 1958, s. 106.

${ }^{33}$ Wróblewski 1958, s. $104-106$.

${ }^{34}$ Wróblewski 1958, s. 107.

${ }^{35}$ Wróblewski 1958, s. 192.
} 

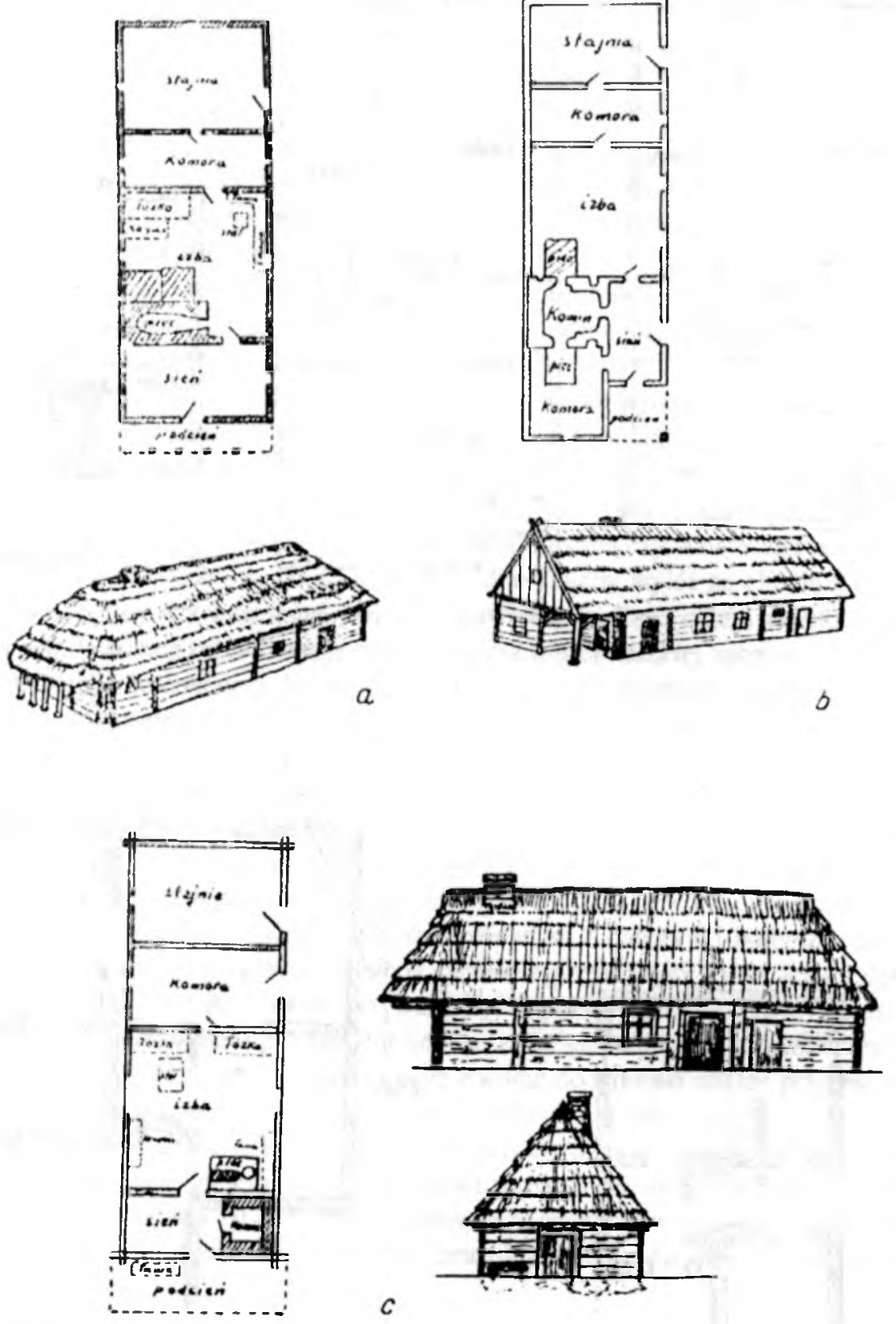

C

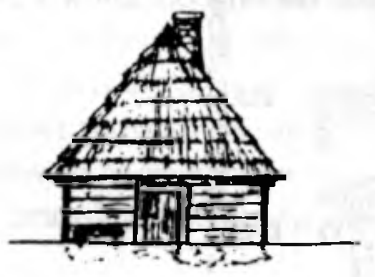

Ryc. 4. Przykłady domostw z podcieniami: a - podcień otwarty, b - podcień narożny, c - podcień przyzbowy (wg Wróblewski 1958)

Abb. 4. Beispiele der Häuser mit Lauben: a - offene Laube, b - Ecklaube, c - Erdbanklaube (nach Wróblewski 1958) 

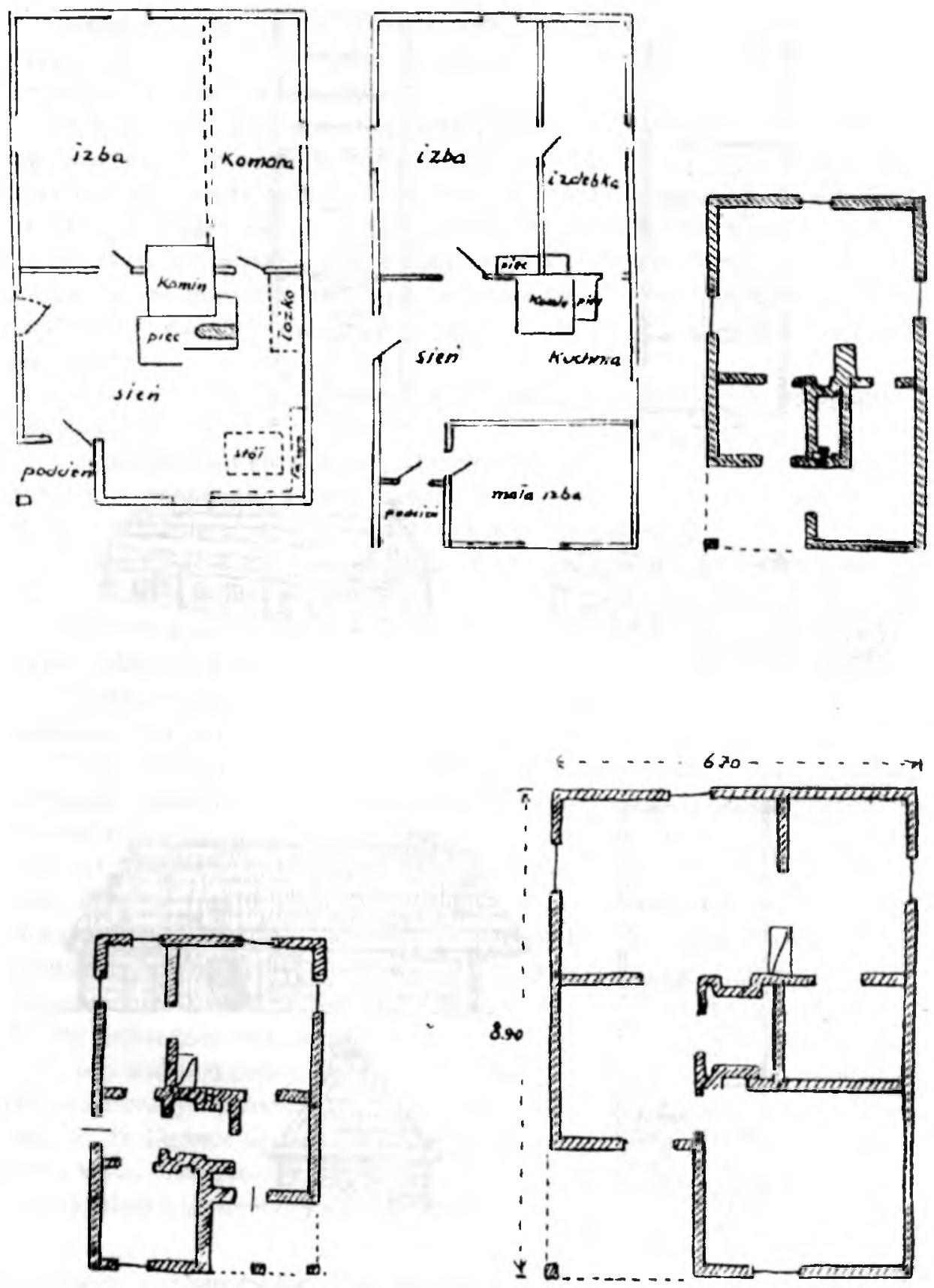

Ryc. 5. Przykłady planów domostw z podcieniem narożnym (wg Wróblewski 1958) Abb. 5. Beispiele der Pläne von Hăusern mit Ecklaube (nach Wróblewski 1958) 
Podcień w chacie pełnił wieloraką rolę. Podstawową była zapewne osłona drzwi wejściowych $^{36}$ oraz ścian przed zamakaniem i niszczeniem. Bardzo istotne było jego znaczenie jako miejsca pracy, wykonywania domowych robót gospodarczych w okresie, gdy nie zostało jeszcze w wystarczający sposób rozwiązane oświetlenie wnętrza domostwa (o czym dalej). Łatwiej zapewne było dokonywać obróbki drewna czy innych surowców w sposobnym temu podcieniu niż w ciemnej, źle oświetlonej izbie. T. Wróblewski podkreśla na przykładzie analogii etnograficznych, iż za takim wykorzystaniem podcienia przemawia to, że najdłużej utrzymywał się przy warsztatach rzemieślniczych, w izbach zaś nie było tradycyjnego miejsca do wykonywania takich robót ${ }^{37}$. Przy okazji warto zwrócić uwagę na rolę zabudowanej sieni w domu 4, która jako przedłużenie podcienia mogła spełniać funkcję miejsca wykonywania wielu czynności gospodarczych $w$ dni chłodniejsze. Tam też mogły być przechowywane narzędzia pracy, częściowo być może rozwieszone na ścianach. I wreszcie nie mniej ważna była funkcja podcienia jako miejsca wypoczynku, podkreślana zarówno przez literaturę etnograficzna, jak i informatorów T. Wróblewskiego $^{38}$. To tu można było po pracy usiąść na wieczorną czy świąteczną pogawędkę zarówno w czasie upałów, jak i niepogody, albo choćby wyjść na chwilę z ciasnej, zadymionej izby, by odetchnąc świeżym powietrzem. Poza celem czysto użytkowym pełnił podcień także funkcję estetyczną, tak bliską ludzkiej naturze.

$\mathrm{W}$ bardzo interesującą konstrukcję związaną z podcieniem układa się zespół 3 słupów znajdujących się poza obszarem analizowanego domostwa, przy jego północno-wschodnim narożniku. Jest to zapewne pozostałość po „swoistym” przyłapie (czasem tym terminem określano również sam podcień narożny, głównie w Wielkopolsce - por. Wróblewski 1959), czyli dobudowanym daszku. Był on konstruowany w chatach o dachu dwuspadowym, na wysokości podstawy trójkąta szczytowego. Funkcja przyłapu polegała na ochronie ściany szczytowej przed zaciekaniem ${ }^{39}$. Słupy 19 i 20 w przyłapie z Kościelisk rozstawione są z daleka od budynku, ale dozwolone było również sadowienie słupa szczelnie przylegającego do ściany domostwa - jak słup 21. Taki wariant nazywany był w polskiej ciesiołce „przyłapem pojedynczym,40. Omawiany przyłap stał umieszczony przed otwartymi przestrzeniami podcienia, mając bez wątpienia za zadanie chronić dodatkowo obszar przezeń osłonięty przed opadami atmosferycznymi i wodą spływającą $z$ dachu domu.

Wejście do chaty 4 w Kościeliskach znajdowało się zapewne w północnej ścianie, skryte pod podcieniem. Być może drzwi prowadzące do domu były rozmieszczone między słupami 10 i 11 oraz położonym naprzeciw nich słupem 18. Prześwit między nimi wynosi ok. $90 \mathrm{~cm}$. Bardzo prawdopodobny jest brak w tym miejscu

\footnotetext{
${ }^{36}$ Wróblewski 1958, s. 125, 135.

${ }^{37}$ Wróblewski 1958, s. 217.

${ }^{38}$ Wróblewski 1958, s. 103, 125.

${ }^{39}$ Wróblewski 1958, s. 107.

${ }^{40}$ Wróblewski 1958, s. 106.
} 
konstrukcji jakichś solidnych, masywnych drzwi. Mógł tu jednak funkcjonować przynajmniej wykonany w konstrukcji plecionkowej plotek, chroniący mieszkańców przed wchodzeniem do domostwa zwierząt. Słup 10 pełniłby wówczas podwójną funkcję: $z$ jednej strony wzmacniającą i stabilizującą konstrukcję dachu, pozbawionego na szerokości występowania podcienia oparcia ściany, jak również z drugiej strony wiatrochronu, chroniącego wnętrze domu przed silnym bocznym wiatrem. Główną izolację termiczną izby stanowiłaby w takim ujęciu jakaś konstrukcja, najprawdopodobniej zasłona uszyta ze skór zwierzęcych, a rozwieszona w wejściu $\mathrm{z}$ sieni do izby, pomiędzy słupami 14 a 18 . Tego typu kotara spełniałaby o wiele lepiej funkcję „termostatu” niż zapewne niezbyt szczelne drzwi. Tłumaczyłoby to również obecność słupa 14 na przedłużeniu ściany wschodniej budynku.

We wnętrzu chaty, w jej pólnocno-zachodnim narożniku, w okolicy słupów 4 do 7, funkcjonowało palenisko. Gęste posadowienie słupów w tym miejscu zdaje się tę tezę potwierdzać. Jeśli bowiem przyjmujemy bliskie usytuowanie otwartego źródła ognia przy konstrukcji drewnianych ścian, musiało istnieć jakieś ich zabezpieczenie przed ewentualnym pożarem. I. Jadczykowa sugeruje w takich wypadkach stosowanie wylepiania od wewnątrz grubą warstwą gliny partii ściany sąsiadującej $\mathrm{z}_{\text {paleniskiem }}{ }^{41}$. Powoduje to zwiększenie masy takiej ściany, a co za tym idzie zmniejszenie stabilności takiego odcinka. W związku z powyższym następowała konieczność dodatkowego wzmocnienia takiego newralgicznego punktu, czego pozostałościa, z dużą dozą prawdopodobieństwa, są dołki posłupowe 5 i 7.

Ponieważ większość badaczy osadnictwa uważa, iż światło dzienne docierało do domostw przez drzwi, w opisywanym domostwie musial panować głęboki półmrok, rozjaśniany tylko przez płomień ogniska lub ewentualnie jakiejś lampy tłuszczowej. Generalnie trudno mówić o możliwości stosowania okien w domach ludności kultury przeworskiej. Panuje przekonanie, iż takowych raczej nie było ${ }^{42}$. Jednakże jakoś musiano przecież radzić sobie z potrzebą rozjaśnienia wnętrza chaty. Choćby tylko po to, by móc pracować w niej zimą lub podczas słoty, kiedy prace domowe w podcieniu stawały się już niemożliwe. Takie wykorzystanie przestrzeni mieszkalnej w omawianym domu sugeruje znalezisko przęślika (w palenisku) oraz płyty szlifier$\mathrm{czej}^{43}$. Podczas zwiedzania zrekonstruowanych osad palafitowych w Unteruhldingen koło Meersburga nad Jeziorem Bodeńskim (Badenia-Würtembergia), zwróciłem uwagę na sposób, w jaki poradzili sobie $\mathrm{z}$ tym problemem archeolodzy niemieccy w rekonstrukcji chat $z$ okresu neolitu i brązu. Otóż w ścianach domostw pozostawione były prześwity, w których umieszczono ramki z rozpiętym na nich pergaminem. W chatach mimo „mrocznej atmosfery” można było jednak wszystko bez problemu widzieć. Być może rzeczywiście w podobny sposób (lub bardziej prymitywnie) radzili sobie budowniczowie pradziejowi. Osobiście uważam, iż chaty musiały

\footnotetext{
${ }^{41}$ Jadczykowa 1981, s. 198.

42 Jadczykowa 1981, s. 233.

${ }^{43}$ Hufnagel 1940 , s. 100.
} 
być zaopatrzone w coś w rodzaju okna pełniącego jednocześnie funkcję świetlika, otworu wentylacyjnego oraz być może komina, mimo iż uważa się, że funkcję komina spełniał dymnik - miejsce lączenia się sochy ze ślemieniem ${ }^{44}$. Pozostałością takiej konstrukcji mógł być wąski słup nr $3 \mathrm{w}$ ścianie zachodniej. W przestrzeni pomiędzy słupami 2 i 4 umieszczony mógł być niższy od nich słup 3, służący jako oś stabilizująca ściankę pomiędzy nimi, zbudowaną np. w konstrukcji szachulcowej. Na końcu słupa 3 mogła być umieszczona belka poprzeczna. Całość powierzchni pomiędzy słupami 2-3 i 3-4 oraz podłożem a tą belką wypełniono ścianką. Przestrzeń pozostawiona między sumikiem a belką stropową oraz słupem 2 i 4 mogła wówczas pełnić funkcję okienną (ryc. 6), dostarczając światło dzienne do wnętrza domu. Przestrzeń taka nie musiała (choć mogła) być zasłaniana, spełniając dodatkowo dwie funkcje, o których wspominałem (proszę zwrócić uwagę na bliskość paleniska!). Na okres zimy i dużych mrozów otwór taki mógł być uszczelniany np. rodzajem zasłony.

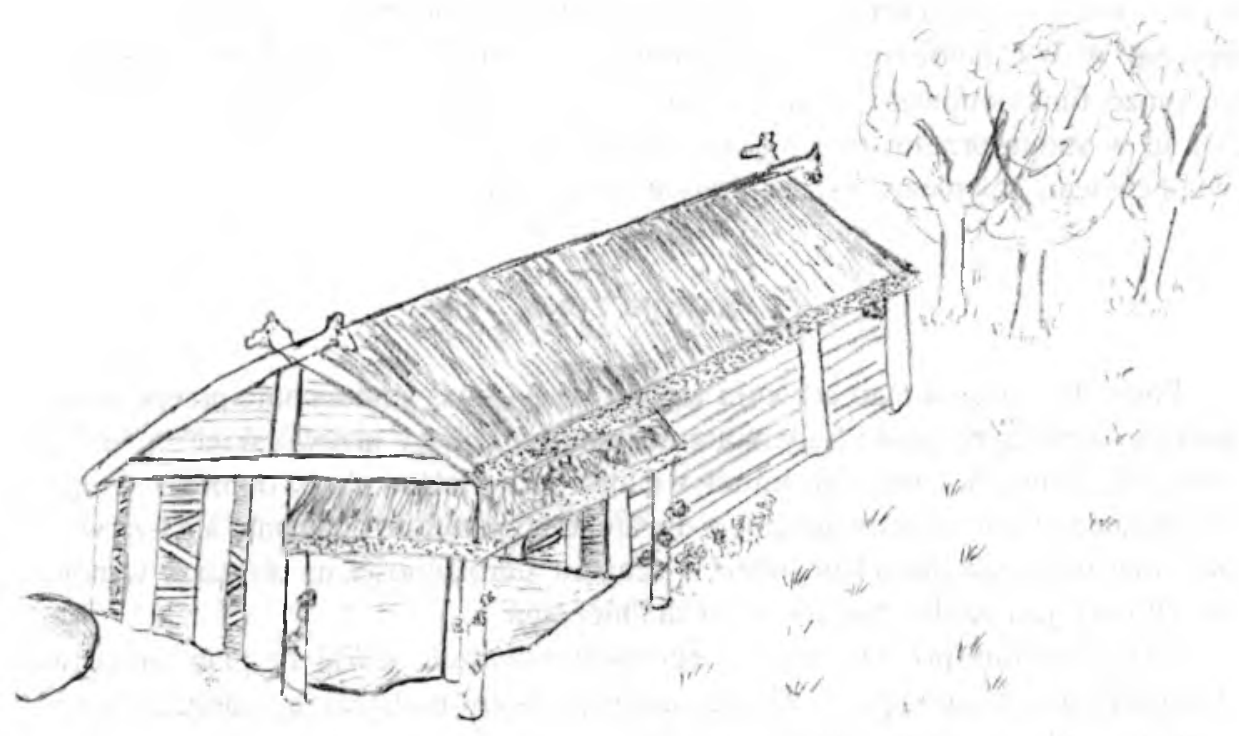

Ryc. 6. Plastyczna rekonstrukcja wyglądu domostwa $\mathrm{nr} 4 \mathrm{w}$ Kościeliskach Abb. 6. Plastische Rekonstruktion des Aussehens des Hauses Nr. 4 in Kościeliska

Z powyższych rozważań wyłania się obraz budynku odkrytego podczas badań w 1937 roku jako naziemnego domu jednoizbowego z przylegającą doń sienią $\mathrm{i}$ podcieniem narożnikowym, zaopatrzonym w osłaniający je przyłap (ryc. 7). Ściany domostwa zbudowano w konstrukcji słupowej, przy użyciu techniki sumikowo-łątko-

\footnotetext{
${ }^{44}$ Jadczykowa 1981, s. 233.
} 


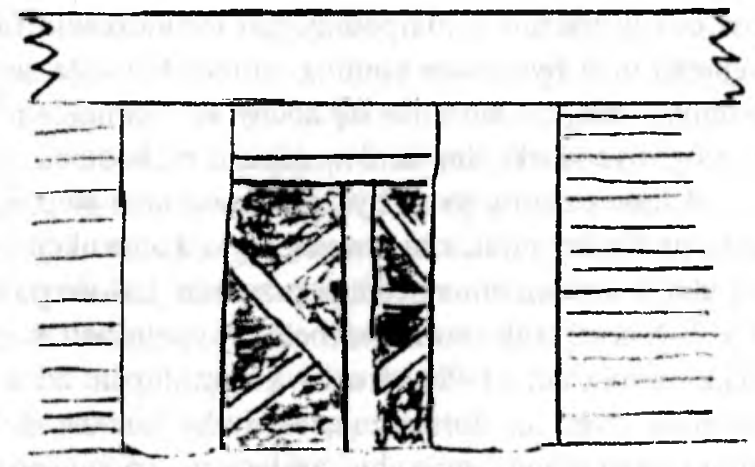

Ryc. 7. Próba rekonstrukcji otworu okiennego w domostwie nr 4 w Kościeliskach Abb. 7. Rekonstruktionsversuch der Fensteröffnung im Haus Nr. 4 in Kościeliska

wej w połączeniu z konstrukcją ramowa, $\mathrm{z}$ dachem opartym na półsochach, krytym strzechą. W wydzielonym, zabezpieczonym miejscu domostwa płonęło palenisko, być może funkcjonowało $\mathrm{w}$ nim w zachodniej ścianie szczytowej małe okienko. Była to w sumie przestrzeń kipiąca codziennym życiem ludzi, którzy tu pracowali i wypoczywali, również w owym miejscu „cieniem krytym”.

\section{ZAKOŃCZENIE}

Pomysł napisania tego artykułu zrodził się podczas studiowania przeze mnie literatury dotyczącej osad i budownictwa ludności kultury przeworskiej na ziemiach polskich. Zdumiało mnie, iż mimo wielości materiałów obraz domostw ludności omawianego ugrupowania nadal jest dla archeologa trudno dostępny, a nasza wiedza na temat tego, jak mieszkali ludzie u schyłku starożytności na obszarze współczesnej Polski, jest bardzo powierzchowna i niepełna.

Odpowiednim przykładem dla tego typu rozważań okazal się plan domostwa 4 z Kościeliska, z jego specyficznym, narożnikowym podcieniem osłoniętym dodatkowym gankiem. Próba odtworzenia jego wyglądu powiązana była $\mathrm{z}$ kwerendami w literaturze zarówno archeologicznej, jak i etnograficznej. Już sama konstrukcja podcienia w typie narożnikowym okazała się stanowić nie lada rarytas, gdyż jak się okazało, mimo dość licznego występowania w starszej architekturze wiejskiej, popularność zdobyła ona dopiero $w$ XIX-XX wieku ${ }^{45}$. W przypadku Kościelisk mamy być może do czynienia $\mathrm{z}$ najstarszym (udokumentowanym) przykładem zastosowania podcienia narożnikowego na ziemiach polskich! Okazuje się bowiem, iż mimo wzmiankowania możliwości funkcjonowania tego typu konstrukcji przy budynkach pradziejowych, same podcienia pozostały na marginesie zainteresowania badaczy,

\footnotetext{
${ }^{45}$ Wróblewski 1958, s. 128, 192.
} 
a wręcz spychane były w niebyt ${ }^{46}$. Teoretycznie chaty tej konstrukcji nie powinny być ewenementem w budownictwie pradziejowym. Słupy stawiane po zewnętrznej stronie ścian chroniły je przed rozsuwaniem się, dźwigały główny ciężar dachu ${ }^{47}$. Na dobrą sprawę niewiele jednak wiadomo o powszechności czy też unikatowości tego rozwiązania technicznego w budowlach ludności kultury przeworskiej. Możliwe, iż ponowne bliższe przyjrzenie się pozostałościom tych domostw, jak i ich reinterpretacja mogą dać odpowiedź na to pytanie. Istotną sprawa jest zatem prześledzenie raz jeszcze układów słupów w konstrukcjach budowlanych społeczności kultury przeworskiej. Warto również zwrócić uwagę (tam gdzie jest to możliwe) na występowanie w pobliżu konstrukcji słupowych dużych kamieni, które mogą być śladami funkcjonowania podcienia. Nie wszystkie bowiem chaty miały słupy podcienia wkopane w ziemię. W części z nich wspierały się one właśnie na dużych kamieniach ${ }^{48}$.

Niniejszy artykuł jest propozycją postępowania badawczego, które można zastosować przy próbie rekonstrukcji rozpoznanych wykopaliskowo obiektów mieszkalnych. Działanie takie, oparte także na danych etnograficznych dotyczących budownictwa drewnianego, pozwoliło na w miarę prawdopodobne poszerzenie przedmiotowej problematyki.

\section{BIBLIOGRAFIA}

\section{A. Wy kaz skrótów}

Mat. Star. - „Materiały Starożytne”, Warszawa

PMMAE - „Prace i Materialy Muzeum Archeologicznego i Etnograficznego”, Seria Archeologiczna, Lódź

Spr. Arch. - „Sprawozdania Archeologiczne”, Kraków

\section{B. Literatura}

Dąbrowski K.

1953 Prace archeologiczne w Piwonicach, pow. Kalisz, „Sprawozdania PMA”, t. 5, s. 88-89.

1955 Badania archeologiczne we wsi Piwonice w pow. kaliskim $w$ roku 1954, Spr. Arch., t. 1, s. $49-63$.

1956a Wyniki badań powierzchniowych przeprowadzonych $w$ okolicy Kalisza i wsi Piwonice, pow. Kalisz $w 1952$ [Sum. Results of 1952 Surface Inwestigations in the Kalisz Envirous and at Piwonice the Kalisz District], Mat. Star., t. 1, s. 173-178.

1956b Sprawozdanie z prac wykopaliskowych we wsi Piwonice pow. Kalisz w $1953 \mathrm{r}$. [Sum. Report on excavations carried at Piwonice, the Kalisz District (1953)], Mat. Star., t. 1, s. $183-191$.

\footnotetext{
${ }^{46}$ Nosek 1946, s. 291.

${ }^{47}$ Wróblewski 1958, s. 190.

${ }^{48}$ Wróblewski 1958 , s. 149 , ryc. 39 , s. 186 , ryc. 75 .
} 
1958a Osadnictwo z okresu późnolateńskiego i rzymskiego na stan. I w Piwonicach pow. Kalisz [Sum. Settlements of the late La Tène and Roman Period at Piwonice. The Kalisz District], Mat. Star., t. 4, s. 7-89.

1958b Bilans badań archeologicznych osady w Piwonicach pod Kaliszem, „Z otchłani wieków”, R. 24, s. 176-182.

1959 Sprawozdanie z badań terenowych Stacji Archeologicznej IHKM w Kaliszu, przeprowadzonych w 1956 roku, Spr. Arch., t. 6, s. 56-67.

1964 Badania archeologiczne osady lateńsko-rzymskiej w Piwonicach w 1962, Spr. Arch., t. 16, s. 95-101.

1965 Badania archeologiczne w Piwonicach w 1963 roku, Spr. Arch., t. 18, s. 101-108.

1968 Badania archeologiczne w Piwonicach w 1965 roku, Spr. Arch., t. 19, s. 99-104.

Godłowski K.

1969 Budownictwo i wielkość osad kultury przeworskiej na Górnym Ślasku [Sum. Buildings and the layout and size of settlements of the Przeworsk Culture in Upper Silesia], „Wiadomości Archeologiczne", t. 34, s. 305-331.

$\mathrm{H} u \mathrm{fn}$ a ge l F.

1940 Eine Siedlung der Guttentager Kultur in Hedwigstein, Kr. Rosenberg, „Altschlesien”, T. IX, s. 84-111.

Jadczykowa I.

1973 Budynki mieszkalne osady produkcyjnej w Przywozie koto Wielunia [Sum. Houses of the industrial settlement at Przywóz, District of Wieluń], PMMAE, nr 20, s. 249-291.

1981 Budownictwo mieszkalne ludności kultury przeworskiej na obszarze Polski [Sum. The houses of the Przeworsk Culture in Poland], PMMAE, nr 28, s. 109-247.

J a żdże ws ka M.

1988 Najciekawsze obiekty na stanowisku kultury przeworskiej w Siemiechowie nad górnq Warta [Sum. Selected features from the Przeworsk culture site at Siemiechów on the upper Warta], PMMAE, nr 20, s. 249-291.

Kaźmierczyk J.

1970 Wroctaw lewobrzeżny we wczesnym średniowieczu. Część II [Rés. La rive gauche de Wrocław au haut moyen - âge], Wrocław - Warszawa - Kraków.

Ko b y lińs ki Z.

1988 Struktury osadnicze na ziemiach polskich u schyłku starożytności i w poczqtkach wczesnego sredniowiecza [Sum. The settlement structures in the Polish lands at the decline of the antiquity and the beginnings of the early middle ages], Wrocław - Warszawa - Kraków Lódż - Gdańsk.

Linde M.S.B.

1858 Stownik języka polskiego, Lwów.

Mosz yńs ki K.

1967 Kultura ludowa Stowian, t. 1, Warszawa.

Nosek S.

1946 Znalezisko w Biskupinie a wspótczesna kultura Slowian, Lud, t. 36, s. 289-312.

P y rg a \& a J.

1972a Budownictwo okresu lateńsko-rzymskiego i wczesnych faz wczesnego średniowiecza na Mazowszu Plockim [Rés. Architecture de la période laténo-romaine et des phases anterieures du haut moyen ages en Masovie de Płock], „Kwartalnik Historii Kultury Materialnej”, t. 20, z. 2, s. 219-241.

1972b Mikroregion osadniczy między Wista a dolnq Wkrq w I w. p.n.e. - IV w. n.e. [Sum. Settlement microregion lying between the Wisła and the lower Wkra in the Roman period], Warszawa. 
Trudzik Z.

1959a Osada z Vw. n.e. w Kościeliskach, pow. Olesno Ślaskie [Zus. Eine Siedlung aus dem V. Jahrhundert u.Z. in Kościeliska, Kreis Olesno Śląskie], „Archeologia Śląska” t. III, s. 65-105.

1959b Sprawozdanie z prac wykopaliskowych osady z Vw. n.e. w Kościeliskach, pow. Olesno Śl., „Śląskie Sprawozdania Archeologiczne”, t. II, s. 31-37.

1960 Z prac wykopaliskowych osady z okresu późnorzymskiego w Kościeliskach, pow. Olesno Śl., „Śląskie Sprawozdania Archeologiczne”, t. III, s. 19-29.

Wróblewski T.

1958 Chtopskie budownictwo podcieniowe $w$ Wielkopolsce $w$ XIX $i$ XX $w$. [Zus. Das Bäuerlische Laubenbauwesen in Gross-Polen im 19. und 20. Jh.], „Zeszyty Naukowe UAM”, Archeologia i Etnografia, z. 1, s. 99-222.

\section{„DIE MIT SCHATTEN BEDECKTE STELLE“ IM HAUS NR. 4 AUS KOŚCIELISKA, KR. OLESNO, WOI. OPOLE (VERSUCH EINER REKONSTRUKTION) - PROBLEM DES LAUBENBAUWESENS IN DER PRZEWORSK KULTUR}

\section{Zus a m menf as sung}

Die Ausgrabungen auf der Fundstelle 1 in Kościeliska, Kreis Olesno (Hedwigstein, Kr. Rosenberg) waren im Jahre 1937 und um die Wende der 50ger und 60ger Jahre geführt. Während dieser Ausgrabungen wurden 111 Befunde, darin 48 Wohnhäuser freigelegt. Ein von ihnen war das im Jahre 1937 untersuchte Haus 4. Es lag im nördlichen Teil der Fundstelle, zwischen der Grube 7 und Grube 8, die an das Haus vom Südosten (Grube 7) und Südwesten (Grube 8) anlagen und es teilweise durchschnitten. Der Gebäudeumriß erschien $30 \mathrm{~cm}$ tief vom Niveau des Humus als rechteckige, $6 \mathrm{~m}$ lange (W-E) und 4,7 m breite (N-S) Verfärbungen. In den bisherigen Erarbeitungen war er als zweiteiliges Pfostenhaus (F. Hufnagel), stark vertieftes Grubenhaus (K. Godłowski) oder ein stark vertieftes, zweiteiliges Haus (I. Jadczykowa) interpretiert.

In der Meinung, daß wir hier mit einem oberirdischen Pfostengebäude mit den Wänden in Stănderkonstruktion, vielleicht mit Rahmenkonstruktion (Flechtwerk?) verbunden, mit Giebeldach zu tun haben, wurde beschlossen, das obige Haus erneut zu interpretieren. Der integrale Teil der Hauskonstruktion war eine Einpfosten-Ecklaube in nordöstlicher Hauspartie.

Infolge einer Analyse wurde festgestellt, daß das Haus 4 aus Kościeliska aus vier übereinstimmenden Elementen bestand:

- eine ungefähr quadratische Hauptkammer, begrenzt mit Eckpfosten 1, 6, 8, 14 mit Abmessungen ca. $4 \times 3,8 \mathrm{~m}$, was eine Fläche von ca. $15 \mathrm{~m}^{2}$ gibt (es wäre eine Fläche, die der dickeren Kulturschicht entspricht),

- ein Flur zwischen den Pfosten 11, 13, 14 und 18, mit Abmessungen ca. 1,2 ×1,75 m, was ca. $2 \mathrm{~m}^{2}$ Flache gibt,

- eine Ecklaube, für deren Konstruktion der Pfosten 9 am wichtigsten ist, und die eine Fläche von ca. $3 \mathrm{~m}^{2}(1,5 \times 2,1 \mathrm{~m})$ verdeckte,

- ein Vordach ohne Pfosten, angelehnt an die Pfosten 19, 20 und 21, das den offenen, außerhalb des Hauses herausragenden Raum der Laube verdeckte.

Beim Besprechen der Hauskonstruktion wurde auch das Problem ihrer inneren Beleuchtung und Lage des Eingangs überlegt, die mit dem Funktionieren der Laube beim Haus verbunden waren. 
Dieser Arbeit liegen sowohl die archäologische Literatur, die sich mit dem urgeschichtlichen Bauwesen beschäftigt, als auch ethnographische Positionen, welche die Problematik des Volksbauwesens aus Holz besprechen, zugrunde.

Ein Erfolg der Überlegungen sind eine erneute Interpretation der bereits veröffentlichten Unterlagen und Vorschlag eines gewissen Forschungsverfahrens, dessen Ergebnis die Beweisung des Funktionierens von Ecklauben im Bauwesen der Bevölkerung der Przeworsk Kultur ist. Im Ergebnis haben wir hier wahrscheinlich mit dem ältesten dokumentierten Beispiel einer solchen Konstruktionslösung auf polnischem Gebiet zu tun.

Übersetzt von Matgorzata Zdzienicka 